\section{ЗАРУБЕЖНЫЙ ОПЫТ ИСПОЛЬЗОВАНИЯ ПРОЦЕССУАЛЬНЫХ ПРЕЗУМПЦИЙ}

Аннотация:

В статье определяется, какую роль выполняют презумпции в зарубежном законодательстве. Существуют две общепризнанные модели гражданского судопроизводства: следственная и состязательная. Наиболее яркими представителями вышеуказанных моделей производства являются Франция, Германия (следственная модель) и Англия, США (состязательная модель). В каждой из приведенных стран концепция правовых презумпций реализована по-своему. Презумпции используются вместе с самобытными чертами гражданского процесса. Различия в реализации подходов к истине в следственной и состязательной моделях судопроизводства порождают соответствующие проблемы, связанные с процессуальными презумпциями. При этом на правовые презумпции оказывают влияние и современные условия: развитие электронного правосудия, внимание к медиативным соглашениям и др. Данные факторы вызывают соответствующую необходимость выделения новых презумпций в зарубежном законодательстве. Анализируя иностранный опыт, автор приходит к выводу, что некоторые презумпции могут быть использованы и в российском законодательстве.

Ключевые слова:

презумпции, правовые предположения, презумпции в иностранном праве, зарубежный опыт использования презумпций, французское доказательственное право, немецкое доказательственное право, американское доказательственное право, английское доказательственное право.
Keywords: presumptions, legal assumptions, presumptions in the international law, international practices in presumptions, French law of evidence, German law of evidence, American law of evidence, English law of evidence.

Презумпции - это необходимая логическая конструкция, которая используется в российском законодательстве. Выделение презумпций как самостоятельного вида норм подразумевает, что правовые предположения обладают специфическими функциями и выполняют особую роль в правовом регулировании. Как правило, презумпция может выступать в качестве процессуальной льготы, средства экономии, гарантии правильного рассмотрения спора в суде. В статье автором предпринята попытка раскрыть, какую смысловую нагрузку имеют презумпции в зарубежном законодательстве.

Франция. Французское законодательство признает презумпции, им посвящена отдельная статья (ст. 1349) в Гражданском кодексе Франции. Правоведами подчеркивается, что правовые презумпции связаны как с материальным, так и с процессуальным правом, влияя на бремя доказывания [1]. Презумпции были реципированы французским законодательством из римского права, и хотя рецепция произошла давно, в рамках современных реалий имеются определенные проблемы с их использованием.

Существует противоречие между теорией и практикой по отношению к презумпциям. Следует пояснить, что во французском законодательстве больше реализована концепция объективной истины. Это означает, что решение должно быть максимально приближено к реальности, все обстоятельства дела обязательно устанавливаются судом. Противоречие заключается в том, что концепция презумпций все-таки подразумевает под собой отход от действительности, правовые предположения не являются доказательствами в полном смысле этого слова, так как недостаточно достоверно отражают события, происходящие в реальности. 
При этом необходимо учитывать, что активное усиление значения электронного правосудия делает более актуальным вопрос существования презумпций во французском законодательстве. Фактически электронных документов, электронных подписей как средства волеизъявления в реальности нет. Их существование предполагается в виртуальном мире. Презюмируется, что электронные подписи, электронные документы соответствуют бумажным оригиналам.

Несмотря на противоречие, во французском законодательстве существует электронная подпись, ее довольно активно используют по назначению на практике. Хотя можно подписаться разными способами, законодатель хотел принять во внимание тот фракт, что использование электронных подписей имеет определенный уровень надежности, который должен быть соблюден. В частности, можно привести наиболее известные плюсы электронной подписи, которая гарантирует, что документ является конфиденциальным и достоверным (без нарушения целостности). Помимо этого, имеются дополнительные преимущества в виде безотзывности (документы хранятся в серверах судов) и более надежной идентификации автора. Последние два атрибута достаточно значимы, и именно по этой причине некоторые правовые системы, помимо Франции, также обеспечили условия для использования электронных подписей.

В российском законодательстве активно внедряются электронные технологии. Принятие федерального закона «Об электронной подписи», изменения Гражданского процессуального и Арбитражного процессуального кодексов тому подтверждение. Вполне возможно говорить о том, что на настоящий момент теоретически существует презумпция истинности электронных доказательств, раз их признает действующее законодательство. Предполагается, что электронный документ, принятый судом, будет тождественным документу на бумажном носителе.

Германия. В Гражданском процессуальном кодексе Германии имеется положение относительно презумпций (ст. 292). Если закон устанавливает предположение о существовании факта, то доказательство противного является допустимым. Поэтому должны быть представлены доказательства, которые полностью убеждают суд в обратном. Опровержение может производиться по ходатайству о допросе стороны судом. Исходя из этого, можно сделать вывод, что презумпции являются опровержимыми. Поскольку опровержимая правовая презумпция приводит к полному изменению бремени доказывания, происходит своеобразная инверсия. Поэтому, для того чтобы опровергнуть презумпцию, должны быть представлены все необходимые доказательства, которые убедят суд в обратном. Презумпция является опровергнутой в том случае, если недействительность предполагаемого фракта представляется полностью доказанной достоверными доказательствами. Судья должен быть убежден в некорректности использования презумпции в данном случае.

В теории выделяются и неопровержимые презумпции [2]. Если в рамках дела используется неопровержимая презумпция, как правило, опровергнуть ее, доказать обратное положение дел не представляется возможным. Суд в своей деятельности старается избегать сбора доказательств и связанных с ними трудностей доказывания обстоятельств дела. Примером неопровержимой презумпции в Законе о разводе является § 1566 абз. 2 БГБ (Германского гражданского уложения): «Неопровержимо предполагается, что брак потерпел неудачу, если супруги проживали раздельно в течение трех лет». Сам фракт проживания супругов отдельно друг от друга является основанием для расторжения брака.

Также как самостоятельный вид выделяются договорно-согласованные презумпции [3] стороны сами договариваются о признании фактов посредством подписания договоров. Можно провести аналогию с российским законодательством - медиативное соглашение, послужившее основанием мирового соглашения. Презюмируется волеизъявление сторон, а также признание фактов, прав и обязанностей при заключении медиативного соглашения.

США. В США часто используют такой термин, как prima facie, который тесно связан с процессуальными презумпциями. Существует несколько подходов к пониманию prima facie [4]. В каждом штате США по-разному воспринимают этот термин из-за особенностей законодательства конкретного штата.

В первом подходе под prima facie понимают достаточное количество доказательств для того, чтобы передать дело на рассмотрение присяжным заседателям, на основании чего они уже принимают решение. Это представляет собой определенный критерий достаточности доказательств. Например, это могут быть неоспоримые доказательства, подтверждающие непричастие стороны к причиненному ущербу, или судебная экспертиза, опровергающая отцовство. Усмотрение судьи в данном случае имеет большое значение, так как именно он решает, когда передать дело. Судья делает предположение о том, что предоставленные доказательства имеют наиболее важное значение и полностью отражают ретроспективную картину произошедших событий. Остальные доказательства неистинны и будут только мешать принятию решения присяжными. Как видно, это понятие имеет связь с презумпциями, так как имеется предположение в отношении обстоятельств дел. 
Второй подход содержит предположение по поводу конкретных обстоятельств дела. Предположение будет являться истинным, если противоположная сторона не опровергнет его. Prima facie довольно часто используют для того, чтобы доказать определенные намерения, мотивы. Если у стороны при обыске нашли довольно большое количество копий фильмов, вполне логично, что такой объем нелицензионной продукции в дальнейшем был бы реализован. Prima facie case - это несколько предположений, которые возникают в деле, формируя собой единый общий вывод. В данном случае возникает частная презумпция, которая дает преимущество одной из сторон, и если она не будет опровергнута, то решение будет вынесено в пользу соответствующей стороны. Противоположная сторона не выиграет дело, даже если доказательная ценность представленных ею доказательств уравновешивает доказательную ценность доказательств стороны, в пользу которой принята презумпция. Ответчик должен иметь дополнительный доказательный вес, равный искусственному весу, установленному презумпцией. В результате противник должен предоставить больше доказательств. Prima facie evidence - предположение в отношении конкретного факта. Как правило, это имеет значение для установления промежуточных обстоятельств, которые в дальнейшем способствуют разрешению дела.

Следует напомнить, что в американском гражданском процессе предусмотрена возможность рассмотрения дела присяжными заседателями. В случае участия присяжных в рассмотрении дела судья в обязательном порядке дает инструкции насчет презумпций, существующих в рамках спора. Как правило, судья обязательно указывает, что согласно американской доктрине доказывания презумпция сама по себе является разновидностью доказательств [5, p. 1480].

Термин «презумпция» склонен ввести в заблуждение присяжных, поскольку может показаться, что это понятие не что иное, как искусственная малозначимая конструкция. Сложность работы с презумпциями заключается в том, что, как правило, присяжные привыкли работать с вещественными доказательствами. Сам американский гражданский процесс рассчитан на яркие красноречивые доказательства, легкие в понимании. В тех случаях, когда считается необходимым компенсировать нежелание присяжных уделять должное внимание косвенным доказательствам, судья может отметить, что факт В создает допустимый вывод о Р или какой-либо другой форме комментария к доказательствам.

Англия. В английском праве можно выделить пять видов презумпций.

Первый вид - убедительные презумпции. Для того чтобы доказать фракт А, суд презюмирует, что фракт В реально существует. Данный вид презумпций представляется опровержимым. Сторона, опровергающая подобную презумпцию, как правило, несет на себе процессуальные риски, в случае если ей не получится убедить суд в обратном. Наиболее известная презумпция, существующая в английском праве, - презумпция здравомыслия. Предполагается нормальным, что все люди здравомыслящие. Факт В, признаваемый судом, является максимально приближенным к реальности и полностью отражает окружающую действительность. С помощью убедительных презумпций устанавливается наиболее четкая ретроспектива событий.

Второй вид - доказательственные презумпции. Здесь суд делает заключение, что фракт В существует, поскольку процессуально доказан факт А. При этом фракт В можно считать как существующим, так и несуществующим. Можно провести аналогию с презумпцией причинителя вреда: сам факт наличия вреда говорит о том, что виновен ответчик, и презюмируется, что вред причинен им. При этом возможна ситуация, когда ребенок причинил вред другому лицу, ответчиками в данном случае будут являться родители ребенка. Хотя последние не причиняли непосредственно вред истцу, отвечать будут именно они.

Третий вид - неопровержимые правовые презумпции, предусмотренные статутами. Эти предположения не могут быть опровергнуты. Они в большинстве случаев являются закрепленными в законодательстве нормами права. Как видно, в английском праве отсутствует спор о существовании неопровержимых презумпций. В российской правовой системе данная проблема активно обсуждается. Отмечалось, что предположение в обязательном порядке должно иметь возможность (даже очень низкую) быть опровергнутым. Также сама по себе конструкция неопровержимой презумпции очень схожа с фикцией, что вызывает трудности в их разграничении.

Четвертый вид - разрешительные презумпции. Доказывание факта А позволяет суду считать фракт В доказанным. Эти презумпции также закреплены в статутах. Особенность данных презумпций заключается в том, что, помимо того что они содержатся в законодательных актах, ими подробно регулируются порядок разрешения спора и в них содержатся прямые указания для суда. Разрешительные презумпции применяются судом в обязательном порядке, так как статуты являются важнейшим первоисточником норм.

Пятый вид - презумпции фракта, в основе которых лежит повседневный опыт. Они не содержатся в праве, но активно используются в судебной деятельности. Все суды будут делать один и тот же вывод из тех же самых предварительных фрактов. Можно провести аналогию с фактическими презумпциями, выделяемыми российскими процессуалистами. Пример - презумпция продолжительности жизни. 
Подводя итог, можно сделать вывод, что все рассмотренные правовые системы признают существование презумпций. При этом имеются проблемы, связанные с реализацией презумптивных норм, вызванные особенностями гражданского процесса в этих странах. Соответственно, способы преодоления этих проблем различаются. Так, например, правоприменитель уделяет особое внимание презумпциям, указывая на фракт их использования в деле (США). Возможно также игнорирование противоречий в теории через закрепление презумпций в законодательстве (Франция).

Как видно, презумпции активно используются иностранными правовыми системами. Более того, создаются такие презумпции, которые не существуют в российском законодательстве, например презумпции достоверности электронных доказательств, договорно-согласованные презумпции и др. Учитывая произошедшие изменения и тенденции в современном праве, усиление значения электронного документа оборота, популяризацию медиативных соглашений, ряд зарубежных презумпций можно со временем признать и в российском законодательстве.

\section{Ссылки:}

1. Gautrais V. Fictions et présomptions: outils juridiques d'intégration des technologies // Sécurité juridique et sécurité technique: indépendance ou métissage : conférence organisée par le Programme international de coopération scientifique (CRDP/CECOJI). Montréal, 2003.

2. Zivilprozessordnung und Nebengesetze Großkommentar. Band 4: §§ 253-299a / B. Wieczorek, R.A. Schütze, H.-J. Ahrens, D. Assmann, S. Weth. 4. Aufl. Berlin, 2013. 1175 S.

3. Roth H. Die «tatsächliche Vermutung» im Zivilprozess // A Festschrift for prof. Dr. Hakan Pekcanitez. Izmir, 2015. S. 329-344.

4. Herlitz G.N. The Meaning of the Term "Prima Facie" // Louisiana Law Review. 1994. Vol. 55, iss. 2. P. 391-408.

5. Lowe Jr. E.N. The California Evidence Code: Presumptions // California Law Review. 1965. Vol. 53, iss. 5. P. $1439-1493$.

\section{References:}

Gautrais, V 2003, 'Fictions et présomptions: outils juridiques d'intégration des technologies', Sécurité juridique et sécurité technique: indépendance ou métissage: conférence organisée par le Programme international de coopération scientifique (CRDP/CECOJI), Montréal.

Herlitz, GN 1994, 'The Meaning of the Term "Prima Facie"', Louisiana Law Review, vol. 55, iss. 2, pp. 391-408.

Lowe, Jr EN 1965, 'The California Evidence Code: Presumptions', California Law Review, vol. 53, iss. 5, pp. 1439-1493. https://doi.org/10.2307/3478957.

Roth, H 2015, 'Die "tatsächliche Vermutung” im Zivilprozess', A Festschrift for prof. Dr. Hakan Pekcanitez, Izmir, S. 329-344, (in German).

Wieczorek, B, Schütze, RA, Ahrens, H-J, Assmann, D \& Weth, S 2013, Zivilprozessordnung und Nebengesetze Großkommentar, Band 4: §§ 253-299a, 4. Aufl., Berlin, 1175 S., (in German). 